Louisiana State University

LSU Digital Commons

Faculty Publications

Department of Biological Sciences

$4-1-2017$

\title{
Biogeography of a plant invasion: drivers of latitudinal variation in enemy release
}

\author{
Warwick J. Allen \\ Louisiana State University \\ Laura A. Meyerson \\ University of Rhode Island \\ David Cummings \\ University of Rhode Island \\ John Anderson \\ University of Rhode Island \\ Ganesh P. Bhattarai \\ Louisiana State University
}

See next page for additional authors

Follow this and additional works at: https://digitalcommons.Isu.edu/biosci_pubs

\section{Recommended Citation}

Allen, W., Meyerson, L., Cummings, D., Anderson, J., Bhattarai, G., \& Cronin, J. (2017). Biogeography of a plant invasion: drivers of latitudinal variation in enemy release. Global Ecology and Biogeography, 26 (4), 435-446. https://doi.org/10.1111/geb.12550

This Article is brought to you for free and open access by the Department of Biological Sciences at LSU Digital Commons. It has been accepted for inclusion in Faculty Publications by an authorized administrator of LSU Digital Commons. For more information, please contact ir@lsu.edu. 
Authors

Warwick J. Allen, Laura A. Meyerson, David Cummings, John Anderson, Ganesh P. Bhattarai, and James T. Cronin 


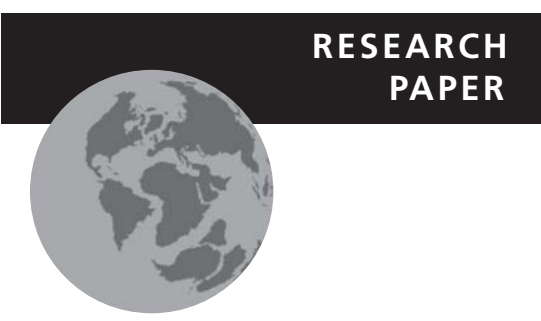

\section{Biogeography of a plant invasion: drivers of latitudinal variation in enemy release}

Warwick J. Allen ${ }^{1 \times \dagger}$, Laura A. Meyerson ${ }^{2}$, David Cummings ${ }^{2}$, John Anderson ${ }^{2}$, Ganesh P. Bhattarai ${ }^{1 \neq}$, and James T. Cronin ${ }^{1}$

${ }^{1}$ Department of Biological Sciences, Louisiana State University, Baton Rouge, LA 70803, USA, ${ }^{2}$ Natural Resources Science, University of Rhode Island, Kingston, RI 02881, USA
${ }^{*}$ Correspondence: Warwick J. Allen, Department of Biological Sciences, Louisiana State University, Baton Rouge, LA 70803, USA.

E-mail: warwick.j.allen@gmail.com

${ }^{\dagger}$ Present address: Warwick J. Allen, The Bio-Protection Research Centre, Lincoln University, PO Box 84, Lincoln, 7647, New Zealand

${ }^{\ddagger}$ Present address: Ganesh P. Bhattarai, Department of Entomology, Kansas State University, Manhattan, KS, 66506, USA

\section{ABSTRACT}

Aim The relationship between herbivory and latitude may differ between native and invasive plant taxa, which can generate biogeographical heterogeneity in the strength of enemy release. Our aim was to compare latitudinal gradients in herbivory between native and invasive plants and investigate whether gradients are driven by local adaptation or phenotypic plasticity.

Location North America.

Methods Using sympatric native and invasive lineages of the wetland grass Phragmites australis and the specialist gall-fly Lipara rufitarsis, we conducted a field survey to examine whether the relationship between herbivory (the proportion of stems galled) and latitude was parallel between lineages. In a subsequent common garden experiment, we assessed whether latitudinal gradients in herbivory were genetically based or driven by phenotypic plasticity.

Results In the field, L. rufitarsis herbivory on the native $P$. australis lineage increased from $27 \%$ of stems galled in southern populations $\left(36.5^{\circ}\right)$ to $37 \%$ in northern populations $\left(43.6^{\circ}\right)$, whereas there was no relationship for the invasive lineage. Similar relationships were evident in the common garden experiment, indicating a genetic basis to latitudinal variation in herbivory. Moreover, the invasive lineage suffered five times less herbivory than the native lineage on average, supporting the enemy release hypothesis. However, a genetic basis to this pattern was absent in the common garden experiment, suggesting that local environmental conditions were responsible for the enemy release observed in nature. Specifically, stem height, diameter and density during the L. rufitarsis oviposition period appeared to be important drivers of herbivory.

Main conclusions Non-parallel gradients in herbivory may help explain the equivocal results of other studies that examine enemy release and biotic resistance at local scales, and can be an important mechanism promoting biogeographical variation in invasion success. We suggest that these latitudinal patterns in herbivory and other species interactions are likely to be a common phenomenon across a range of invaded systems.

\section{Keywords}

Chloropidae, invasive plants, latitudinal gradients, Lipara, phenotypic plasticity, Phragmites, plant-herbivore interactions, plant traits. 


\section{INTRODUCTION}

One of the most general and recognizable patterns in ecology is the latitudinal diversity gradient (Pianka, 1966; Hillebrand, 2004). Ecologists have hypothesized that this phenomenon should contribute to the evolution of stronger species interactions (e.g. herbivory, competition, parasitism, mutualisms) at lower than higher latitudes (Dobzhansky, 1950; Coley \& Aide, 1991; Schemske et al., 2009). However, a meta-analysis by Moles et al. (2011) found a significant negative latitudinal gradient in herbivore damage for only $37 \%$ of studies, while an additional $21 \%$ reported a significant positive latitudinal gradient. Clearly, there is substantial variation in the presence and direction of latitudinal gradients in herbivory, which may have important implications for other ecological processes.

Although evidence regarding the presence and direction of latitudinal gradients is mixed, it is undoubted that species interactions are often important in the establishment and spread of invasive species (Shea \& Chesson, 2002; Mitchell et al., 2006). For example, the enemy release hypothesis is a major and intuitive hypothesis within invasion ecology, consisting of two key predictions: (1) invasive species escape from herbivores which were present in their native range, and (2) invasive species suffer less damage from natural enemies in their introduced range relative to co-occurring native species (Elton, 1958; Keane \& Crawley, 2002). Empirical evidence for the first prediction is generally strong (Colautti et al., 2004; Liu \& Stiling, 2006), but support for the second prediction is equivocal (Colautti et al., 2004; Agrawal et al., 2005; Parker \& Gilbert, 2007; Chun et al., 2010). In this paper, we focus only on the latter prediction. An alternative to enemy release is the biotic resistance hypothesis. In this scenario, natural enemies in the introduced range cause greater damage to invasive species than co-occurring native species (Elton, 1958). Interestingly, evidence supporting this hypothesis is also mixed (Levine et al., 2004; Parker et al., 2006).

Inconsistent support for these contrasting hypotheses (i.e. enemy release and biotic resistance) may stem from the fact that the majority of studies testing them have generally focused on small spatial scales (i.e. a single geographical area). Whereas native species are expected to evolve latitudinal gradients in the strength of species interactions (Dobzhansky, 1950; Coley \& Aide, 1991), expectations for latitudinal gradients involving invasive species could be considerably different. For example, invaders may have had insufficient time to evolve a parallel gradient in interaction strength. Invasive species also often have reduced genetic variation compared with their native range (Dlugosch \& Parker, 2008), which can hinder local adaptation. Moreover, they may be subjected to different selection pressures relative to co-occurring native species (e.g. herbivory levels), which can result in differing evolutionary trajectories. Thus, if sympatric native and invasive plant taxa exhibit dissimilar or nonparallel relationships between herbivory and latitude, this could lead to heterogeneity in the strength of enemy release or biotic resistance at a biogeographical scale (Bezemer et al., 2014; Cronin et al., 2015), which may confound smaller-scale studies. For example, Cronin et al. (2015) examined latitudinal gradients in herbivory from several herbivore guilds on co-occurring native and invasive lineages of the wetland grass Phragmites australis (Cav.) Trin. ex Steudel (Poaceae) in North America. Chewing damage and incidence of internal feeding herbivores was lower on average for the invasive than the native lineage. However, damage decreased with increasing latitude for the native lineage but not for the invasive lineage. Consequently, enemy release was strongest for the invasive lineage at southern latitudes (i.e. lower biotic resistance).

However, it remains unclear whether non-parallel latitudinal gradients in herbivory are genetically based (i.e. owing to natural selection and local adaptation) or phenotypically plastic responses to the local environment (e.g. Woods et al., 2012; Hiura \& Nakamura, 2013; Bhattarai et al., 2016). Combining field surveys and common garden studies is a powerful approach to disentangling these two influences (e.g. Woods et al., 2012; Hiura \& Nakamura, 2013; Bhattarai et al., 2016). For instance, a gradient observed in the field that disappears in the common garden would suggest that phenotypic plasticity is the underlying cause for the gradient. Alternatively, the absence of a gradient in the field but the presence of one in the common garden would suggest that environmental variability obscures evidence of local adaptation.

The goal of this study was to compare the strength and direction of latitudinal gradients in herbivory between native and invasive plants and to investigate whether gradients have an underlying genetic basis or are due to plastic responses to local environmental conditions. We focused on native and invasive lineages of $P$. australis and a specialist gall-forming fly, Lipara rufitarsis Loew (Diptera: Chloropidae). We surveyed $25 P$. australis populations (12 native, 13 invasive) along the east coast of North America from North Carolina $\left(36.5^{\circ}\right)$ to Maine $\left(43.6^{\circ}\right)$ to examine biogeographical variation in the proportion of stems with galls of L. rufitarsis. We also ran a complementary common garden experiment examining L. rufitarsis herbivory of 59 P. australis populations sourced from throughout North America. Based on the enemy release hypothesis and previous studies suggesting the existence of non-parallel latitudinal gradients between the two lineages in the this system (Cronin et al., 2015; Bhattarai et al., 2016), we tested the following predictions: (1) native and invasive $P$. australis lineages will exhibit non-parallel latitudinal gradients in the proportion of stems with galls (i.e. biogeographical heterogeneity in relative strength of herbivory); (2) the proportion of stems with galls will be lower on the invasive than the native lineage in the field (i.e. the enemy release hypothesis); (3) the same patterns will be reflected in a complementary common garden experiment (i.e. patterns of herbivory have a genetic basis); and (4) the proximal mechanism underlying variation in the proportion 
of stems with galls is related to stem characteristics at the time of L. rufitarsis oviposition.

\section{METHODS}

\section{Study organisms}

Phragmites australis is a model organism for studying plant invasions (Meyerson et al., 2016). It is a large-statured perennial grass which forms dense stands in the littoral zone of lakes, rivers and fresh- and saltwater marshes, and is virtually cosmopolitan in its distribution (Lambertini et al., 2006). A native lineage of $P$. australis has been present in North America for millennia and consists of at least 14 different haplotypes (Saltonstall, 2002, 2016; Meadows \& Saltonstall, 2007; Vachon \& Freeland, 2011). However, an invasive lineage of $P$. australis from Europe has spread throughout North America since first appearing in herbarium records around 150 years ago (Chambers et al., 1999; Saltonstall, 2002; Howard et al., 2008; Meyerson et al., 2009, 2012). There is an additional Gulf Coast lineage (Hauber et al., 2011; Meyerson et al., 2012) that is found outside the range of Lipara (Allen et al., 2015) and thus was not included in this study. The cooccurrence of conspecific lineages enables robust and conservative comparisons between native and invasive plants by minimizing phylogenetic differences between taxa.

Herbivory of $P$. australis in North America is mostly attributed to accidentally introduced arthropods, including three species of monophagous and univoltine Lipara gall-flies introduced from Europe: Lipara pullitarsis Doskocil and Chvala, L. rufitarsis and L. similis Schiner (Tewksbury et al., 2002; Allen et al., 2015). Lipara adults emerge in the spring, mated females oviposit on young $P$. australis shoots and the resultant larvae feed internally to induce distinctive cigarshaped galls in the apical parts of the stems (Chvala et al., 1974). A single fully grown larva overwinters inside the senesced stem before pupation occurs in the spring. All three Lipara species in North America attack the native and invasive lineages of $P$. australis (Allen et al., 2015), although higher herbivory has consistently been reported on the former, with up to $80 \%$ of stems per population with galls (Balme, 2000; Lambert et al., 2007; Park \& Blossey, 2008; Allen et al., 2015). Lipara rufitarsis is the most widespread and abundant species, occurring from North Carolina to Maine and inhabiting 79\% of all galls (Allen et al., 2015). Stems infested by Lipara have a reduced size and never produce a panicle (Lambert et al., 2007; Park \& Blossey, 2008; Blossey, 2014; Allen et al., 2015). Based on the frequency of damage and the direct impact on sexual reproduction, Lipara represents one of the most damaging and important herbivores of P. australis in North America (Cronin et al., 2015).

\section{Field survey}

To examine latitudinal variation in the proportion of stems with L. rufitarsis galls, we surveyed 25 P. australis populations (12 native, 13 invasive) along the East Coast of the United
States (Appendix S1 in Supporting Information), where the invasive European lineage first appeared in herbarium records (Saltonstall, 2002). Populations were selected to cover the entire known latitudinal range of L. rufitarsis in North America $\left(36.5^{\circ}\right.$ to $43.6^{\circ}, 789 \mathrm{~km}$; Allen et al., 2015). Determination of lineage was made using chloroplast DNA and the methods of Saltonstall (2002), with modifications outlined in Kulmatiski et al. (2010). In many locales, populations of both native and invasive $P$. australis lineages occurred in the same watershed but were rarely intermixed.

Sampling was conducted when galls were apparent during late summer (28 July-30 August 2012). For each P. australis population, the proportion of stems with a Lipara gall was estimated by walking a single transect from the edge of the patch to the interior and examining the three closest stems every metre for the presence of a gall ( 150 stems in total). To estimate the proportion of stems with a $L$. rufitarsis gall, all galls were collected during the survey, transferred to individual Ziploc bags, and reared in an environmental chamber $\left(25^{\circ} \mathrm{C}, 95 \%\right.$ relative humidity, $16: 8 \mathrm{~h}$ light:dark) (see Allen et al., 2015). Lipara were identified to species based on gall and insect morphology, following Chvala et al. (1974). In this study, we focused exclusively on $L$. rufitarsis because it was the only Lipara species that was widespread and abundant enough to test our predictions.

\section{Common garden experiment}

A complementary experiment was conducted at an established common garden at the University of Rhode Island, Kingston, RI $\left(41.49^{\circ} \mathrm{N},-71.54^{\circ} \mathrm{W}\right)$. We collected data from 59 populations of $P$. australis ( 24 native, 35 invasive), initiated with small cuttings of rhizome material collected from natal populations throughout North America, and ranging in latitude from $29.1^{\circ}$ to $46.1^{\circ}$ (1889 km) (Appendix S2). Native populations belonged to eight different haplotypes, whereas all of the invasive populations used were haplotype M (Saltonstall, 2002, 2016), the predominant invasive haplotype in North America. Six native and seven invasive populations overlapped with those from the field study.

Each population was represented by $12.6 \pm 1.2$ pots (mean \pm SE; range 3-38) and was planted between 2005 and 2011 in 19-1 nursery pots containing Metromix® soil (Sungro Horticulture, Agawam, MA, USA). At yearly intervals, the potted plants were split and repotted to prevent the roots from becoming potbound. Replicate pots within each population were randomly distributed among outdoor plastic pools that were filled with fresh water and were regularly fertilized with Mega Green organic fertilizer (Hydrolysate Company of America LLC, Isola, MI). Plants were grown in the common garden for at least 2 years prior to implementation of the experiment. Because we removed panicles before seeds dehisced, only clonal rhizomatous growth occurred in the garden. Thus, unless somatic mutations occurred over a relatively short time period, it is highly unlikely that evolution took place in response to the local (garden) environment. 
Consequently, any variation among common garden populations was expected to be due to genetic differences that originated in the natal location. Furthermore, by growing the plants under identical conditions from small amounts of rhizome material for at least 2 years prior to the start of our study, maternal effects that might drive differences in herbivory were minimised.

To assess herbivory of $L$. rufitarsis on $P$. australis populations under homogeneous environmental conditions, we first removed all senesced stems from the common garden in the winter of 2012-13. We then seeded the garden on 18 April 2013 with 800 L. rufitarsis galls, sourced from an invasive $P$. australis population $8 \mathrm{~km}$ from the common garden $\left(41.38^{\circ}\right.$ $\mathrm{N},-71.51^{\circ} \mathrm{W}$; Appendix S1). The collected galls were evenly spread throughout the common garden, at a rate of about one gall per pot. Lipara rufitarsis were left to naturally emerge, mate and select stems for oviposition. Plants and galls were allowed to develop naturally over the year.

The proportion of stems infested with Lipara per $P$. australis source population was quantified by inspecting each senesced stem for the presence of a gall during April 2014 (the year after the garden was seeded with $L$. rufitarsis). The number of stems examined per population averaged $125.5 \pm 14.3$ (range 10-432). We set a minimum criterion of 10 stems for a population to be included in the analyses. All galls were collected and inhabitants reared in the laboratory to determine Lipara species identity.

To investigate the proximal factors that affect $L$. rufitarsis herbivory, we collected data on $P$. australis stem characteristics during the period when adult female L. rufitarsis were selecting plants for oviposition (25 May to 10 June 2013; based on Chvala et al., 1974). Stem density, height and diameter were the traits quantified; these were selected because they are known to influence oviposition and performance of gall-forming herbivores (e.g. Prado \& Vieira, 1999; Santos et al., 2008), including Lipara (De Bruyn, 1994; Blossey, 2014). The number of stems per pot were counted and converted to number $/ \mathrm{m}^{2}$. Stem height (measured from the base to the highest point of the stem) and stem diameter (measured at the first internode above the soil using digital callipers) were obtained for a single randomly selected stem in each pot. We set a minimum criterion of three replicate pots for a population to be included in the analyses.

\section{Data analysis}

\section{Field survey}

We tested whether there were latitudinal gradients in the proportion of stems galled by L. rufitarsis and whether they differed between native and invasive $P$. australis lineages. We used a generalized linear model (GLM) with a logit link function and binomial distribution of errors, and included lineage and latitude as explanatory variables. A quadratic term (latitude ${ }^{2}$ ) was also included to evaluate whether the relationship between the proportion of stems with galls and latitude was nonlinear. A nonlinear latitudinal gradient may be expected based upon the range centre hypothesis (Alexander et al., 2007; Woods et al., 2012), which posits that higher plant abundance and herbivore pressure nearer the range centre than the range margins could lead to unimodal patterns in herbivory. Furthermore, the invasive lineage and Lipara both first appeared in the mid-Atlantic (around the centre of our study range) and then spread north and south (Saltonstall, 2002). Consequently, a unimodal relationship may also be expected for the invasive P. australis lineage if time since invasion is an important driver of latitudinal gradients in herbivory (see Bhattarai et al., 2016). Possible interactions between lineage and latitude and lineage and latitude $^{2}$ were also tested, as they were deemed to be potentially important based on previous studies with $P$. australis which showed that non-parallel latitudinal gradients in herbivory between the native and invasive lineage are common (Cronin et al., 2015; Bhattarai et al., 2016).

We used the Akaike information criterion corrected for small sample size (AICc; a measure of the relative quality of a statistical model) to select the most informative model (Burnham \& Anderson, 2010). Candidate models $(n=13)$ were constructed from the full model (lineage, latitude, latitude $^{2}$, lineage $\times$ latitude, and lineage $\times$ latitude $^{2}$ ) using all possible combinations of the variables, but with the restriction that interaction terms could only be included if their main effects were also present in the model. Candidate models were ranked by AICc from lowest to highest value and models with a $\triangle \mathrm{AICc}$ value $\left(=\mathrm{AICc}_{i}-\mathrm{AICc}_{\text {min }}\right.$; the change in AICc between the current and top model) of two or less were deemed to have substantial support (Burnham \& Anderson, 2010). We also report the AICc weights which indicate the weight of evidence (as a proportion) in favour of model $i$ being the best model given the set of plausible candidate models. Finally, if the most highly supported model(s) included a lineage $\times$ latitude or lineage $\times$ latitude $^{2}$ interaction as an important explanatory variable, we subsequently performed separate GLMs for each lineage to characterize relationships between the proportion of stems galled and latitude. Goodness of fit is reported as 1 - (residual deviance/null deviance), comparable in interpretation to the coefficient of determination $\left(R^{2}\right)$ for linear models (Menard, 2000).

Common garden experiment

Using the same GLM and AICc model selection approach outlined above, we tested whether the proportion of stems with a gall was influenced by $P$. australis lineage, latitude and stem characteristics during the $L$. rufitarsis oviposition period. The proportion of stems with a gall was weighted by the total number of stems examined per population to account for potential effects of stem density on our response variables. Thus, our full model included lineage, latitude, latitude $^{2}$, stem density, height and diameter at oviposition, as well as interactions between lineage and each of the other explanatory variables ( $n=275$ candidate models). For each continuous explanatory variable present in the most likely 


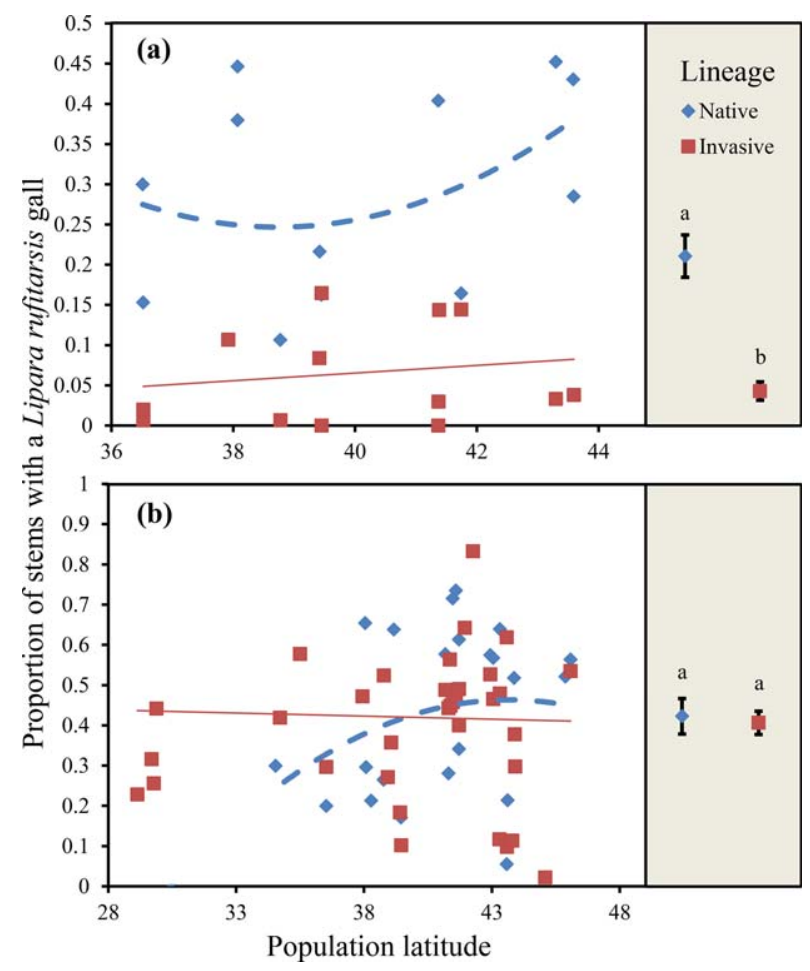

Figure 1 Relationship between latitude and the proportion of stems galled by Lipara rufitarsis for populations of the native and invasive Phragmites australis lineages in (a) the field survey and (b) the common garden experiment. Regression lines are fitted using parameter estimates from separate generalized linear models for each lineage (solid line, invasive; dashed line, native) or from leastsquares regression for nonlinear relationships. Thick lines denote significant relationships between the proportion of stems galled and latitude $(P<0.05$; see Appendix S3). Symbols in the shaded portion of the figure depict the mean $( \pm S E)$ proportion of stems galled for each lineage independent of latitude. Different lowercase letters indicate significant differences between means $(P<0.05)$.

model(s), we again performed separate GLMs for each $P$. australis lineage to characterize relationships with the proportion of stems galled. For variables which did not interact with lineage in the most likely model(s), we performed a single GLM with the $P$. australis lineages combined. Finally, for each explanatory variable in the top AICc models across all analyses, we reported effect sizes (i.e. proportional differences in means or strength of relationship slopes) (Burnham \& Anderson, 2010). All analyses were performed in R 3.3.1. ( $R$ Development Core Team, 2016) using the MuMIn package (Barton, 2016).

\section{RESULTS}

\section{Field survey}

Variation in the proportion of stems galled by L. rufitarsis in the field was best explained by a single model (AICc $=325.7$, $R^{2}=0.674$, AICc weight $\left.=1.0\right)$. This was the full model, including lineage, latitude, latitude ${ }^{2}$, lineage $\times$ latitude and lineage $\times$ latitude $^{2}$ as influential explanatory variables. In the field, the proportion of stems galled by $L$. rufitarsis on native $P$. australis populations $(0.29 \pm 0.04$, mean \pm SE) was nearly five times higher than on invasive $P$. australis populations $(0.06 \pm 0.02)$ (Fig. 1a). The relationship between the proportion of stems galled by $L$. rufitarsis and latitude depended upon the $P$. australis lineage (i.e. the lineage $\times$ latitude and lineage $\times$ latitude $^{2}$ interactions were present in the most likely model). The quadratic relationship between the proportion of stems galled for the native lineage and latitude (based on a separate GLM for this lineage only) was weakly $\mathrm{U}$-shaped and increased from 0.27 at the southernmost site to 0.37 at the northernmost site (latitude ${ }^{2}: \quad z=4.30$, $R^{2}=0.134, P<0.001$; Fig. 1a). Conversely, the proportion of stems galled for the invasive lineage increased by $68 \%$ over its latitudinal range, but this increase was non-significant $\left(z=1.78, R^{2}=0.028, P=0.075\right.$; Fig. 1a).

\section{Common garden experiment}

A single plausible model $(\Delta \mathrm{AICc} \leq 2)$ explained variation in L. rufitarsis herbivory in the common garden $(\mathrm{AICc}=584.4$, $R^{2}=0.640$, AICc weight $\left.=1.00\right)$ and included all terms except the lineage $\times$ stem height interaction. Whereas $P$. australis lineage was an influential variable, the average proportion of stems with a $L$. rufitarsis gall was only slightly higher on the native $(0.43 \pm 0.03)$ than invasive $(0.40 \pm 0.03)$ lineage of $P$. australis (Fig. 1b), representing a $30 \%$ and six-fold increase in herbivory in comparison with the field, respectively. As with the field survey, the effects of lineage on the proportion of stems with galls varied with latitude (i.e. lineage $\times$ latitude and lineage $\times$ latitude $^{2}$ interactions). Separate GLMs for each lineage indicated that the native lineage had a significant nonlinear but generally positive correlation between the proportion of stems galled and latitude (latitude $^{2}: z=3.29, R^{2}=0.047, P=0.001$; Fig. 1b, Appendix S3). The proportion of stems galled doubled (from 0.23 to 0.46 ) from the southern to the northern end of the native lineage distribution $(1281 \mathrm{~km})$. In contrast, no relationship was detected between the proportion of stems galled and latitude for the invasive lineage $\left(z=0.79, R^{2}=0.001, P=0.430\right.$; Fig. 1b). Importantly, these non-parallel latitudinal gradients observed in the common garden were consistent with those observed in the field.

Stem characteristics during the L. rufitarsis oviposition period were very influential in explaining the proportion of stems with galls per source population in the common garden experiment. First, L. rufitarsis herbivory was strongly and negatively correlated with mean stem height, regardless of $P$. australis lineage $\left(z=-15.95, R^{2}=0.362, P<0.001\right.$; Fig. 2a, Appendix S3), decreasing by $82 \%$ over the range of stem heights. Second, basal stem diameter was weakly and positively correlated with the proportion of stems galled, but the slope of the relationship depended on $P$. australis lineage (lineage $\times$ stem diameter interaction in the top model). The correlation was steeper for the invasive $\left(z=6.72, R^{2}=0.095\right.$, 

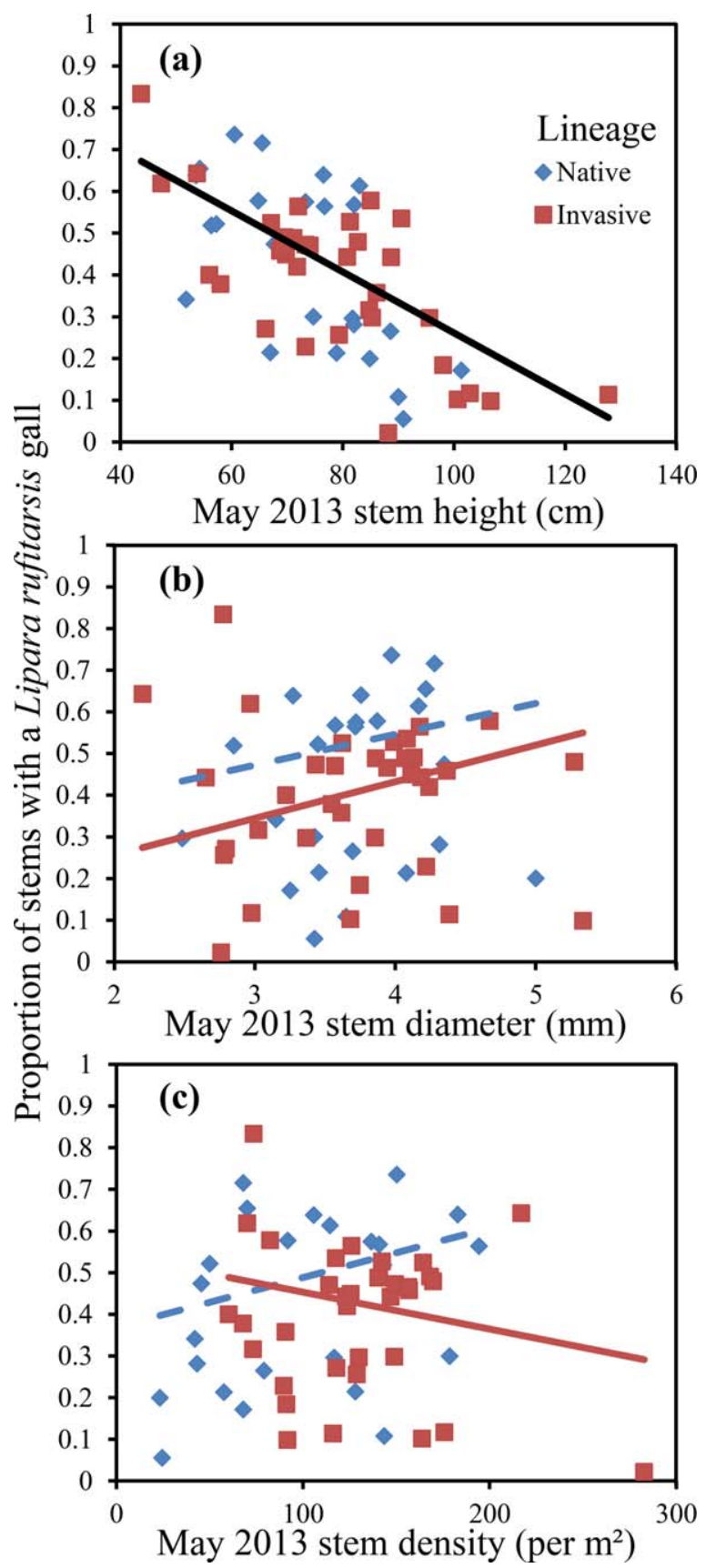

Figure 2 Relationship between the proportion of stems galled by Lipara rufitarsis and (a) stem height $(\mathrm{cm}),(\mathrm{b})$ stem diameter $(\mathrm{mm})$, and (c) stem density (per $\mathrm{m}^{2}$ ) during the L. rufitarsis oviposition period for the native and invasive lineages of Phragmites australis in the common garden experiment. Regression lines are fitted using parameter estimates from generalized linear models for each stem characteristic. Individual lines for each lineage (solid line, invasive; dashed line, native) are shown if the stem characteristic had a significant interaction with lineage in the most likely model. Thick lines denote significant relationships between $L$. rufitarsis herbivory and stem characteristics $(P<0.05$; see Appendix S3).
Table 1 Mean $( \pm$ SE) stem height $(\mathrm{cm})$, diameter $(\mathrm{mm})$ and density $\left(\right.$ per $\mathrm{m}^{2}$ ) for the native and invasive Phragmites australis lineages in the common garden experiment.

\begin{tabular}{lrr}
\hline & \multicolumn{2}{l}{ Phragmites australis lineage } \\
\cline { 2 - 3 } & \multicolumn{1}{l}{ Native } & \multicolumn{1}{c}{ Invasive } \\
\hline Stem height $(\mathrm{cm})$ & $73.50^{\mathrm{a}} \pm 2.77$ & $74.97^{\mathrm{a}} \pm 2.30$ \\
Stem diameter $(\mathrm{cm})$ & $3.71^{\mathrm{a}} \pm 0.11$ & $3.61^{\mathrm{a}} \pm 0.11$ \\
Stem density $\left(\right.$ per $\left.\mathrm{m}^{2}\right)$ & $99.96^{\mathrm{a}} \pm 10.50$ & $124.88^{\mathrm{b}} \pm 6.16$ \\
\hline
\end{tabular}

Different lowercase letters indicate significant differences between lineage means for each stem characteristic $(P<0.05)$.

$P<0.001)$ than native $\left(z=3.35, R^{2}=0.048, P<0.001\right)$ lineage, increasing by $97 \%$ and $43 \%$ over the range of stem diameters for each lineage, respectively (Fig. 2b, Appendix S3). Third, the native lineage exhibited a positive correlation $\left(z=4.88, R^{2}=0.103, \quad P<0.001\right)$ and the invasive lineage exhibited a negative correlation $\left(z=4.77, \quad R^{2}=0.048\right.$, $P<0.001)$ between stem density and the proportion of stems with galls (Fig. 2c, Appendix S3). The proportion of stems galled increased by $51 \%$ over the range of native stem densities and decreased by $39 \%$ over the range of invasive stem densities.

Because stem characteristics during L. rufitarsis oviposition were important predictors of the proportion of stems galled in the common garden, we tested how each stem characteristic varied with respect to lineage, latitude (and the quadratic latitude $^{2}$ ) and their interaction using analysis of covariance (ANCOVA). Stem density was $25 \%$ higher for the invasive $\left(124.9 \pm 6.2\right.$ per $\left.\mathrm{m}^{2}\right)$ than native $\left(100.0 \pm 10.5\right.$ per $\left.\mathrm{m}^{2}\right)$ lineage $\left(F_{1,53}=5.84, P=0.019\right.$; Table 1$)$. However, stem height and stem diameter did not differ between $P$. australis lineages, and none of the stem characteristics varied with latitude of origin of the $P$. australis populations $(P>0.05$ for all tests).

\section{DISCUSSION}

The native lineage of $P$. australis exhibited a positive relationship in the field between herbivory from a specialist stem gall-fly (L. rufitarsis) and latitude, whereas no relationship with latitude was detected for the invasive lineage. These non-parallel gradients resulted in stronger enemy release of invasive $P$. australis from $L$. rufitarsis at more northern latitudes. Latitudinal gradients observed in the field were reflected in the common garden experiment, suggesting an underlying genetic basis to these biogeographical patterns. However, $P$. australis lineage was relatively unimportant in determining the proportion of stems galled per population in the common garden experiment. Instead, stem characteristics (height, diameter, density) measured during the L. rufitarsis oviposition period were the primary determinants of herbivory. This result suggests that the strong difference in the proportion of stems galled between native and invasive $P$. 
australis lineages observed in the field was not genetically based but rather driven by the effects of local environmental conditions on plant growth and the subsequent response of L. rufitarsis. Along with the studies by Cronin et al. (2015) and Bhattarai et al. (2016), our study suggests that genetically based latitudinal gradients in herbivory and qualitative differences in those gradients between sympatric native and invasive plant taxa may be widespread. Moreover, these biogeographical patterns can help explain the equivocal results of other studies that examine enemy release and biotic resistance at local scales, and may be an important mechanism promoting biogeographical variation in invasion success.

\section{Non-parallel latitudinal gradients in L. rufitarsis herbivory}

Although evidence to date is limited to a single plant system, $P$. australis, this study lends support to the idea that enemy release is dependent on biogeography (see also Cronin et al., 2015; Bhattarai et al., 2016). Our prediction that native and invasive $P$. australis lineages exhibit non-parallel latitudinal gradients in the proportion of stems with L. rufitarsis galls was supported. In the field, we found that the proportion of stems with galls in native $P$. australis populations increased by $37 \%$ from our southernmost to our northernmost populations, whereas there was no relationship between the proportion of stems galled and latitude for the invasive lineage. Thus, the difference in herbivory between the two lineages diverged with increasing latitude, resulting in stronger enemy release in the north than the south. These non-parallel gradients between native and invasive lineages were reflected in the common garden experiment. Due to the controlled environment in the common garden, these biogeographical patterns are genetically based rather than the result of phenotypic plasticity, thus supporting our third prediction.

Cronin et al. (2015) and Bhattarai et al. (2016) have previously described biogeographical heterogeneity in the strength of enemy release of invasive $P$. australis in the field and common garden, respectively. These studies focused on oligophagous and generalist herbivores [the mealy plum aphid, Hyalopterus pruni (Geoffroy) and the fall armyworm, Spodoptera frugiperda (J. E. Smith), respectively] or the combined effects of entire herbivore guilds (leaf chewers, internal stem feeders), whereas the current study focused on an obligate specialist of $P$. australis. We expected that local adaptation by native and invasive $P$. australis to a specialist herbivore would be more likely than adaptation to oligophagous or generalist herbivores (Anstett et al., 2014). However, for the native lineage, $H$. pruni exhibited a genetically based negative latitudinal gradient, L. rufitarsis a genetically based positive latitudinal gradient and S. frugiperda showed no evidence of a gradient. Interestingly, the invasive lineage only exhibited a genetically based negative latitudinal gradient for $H$. pruni aphids. These findings concur with those of Kim (2014) who found no clear distinction between specialist and generalist herbivores in the likelihood that their host plants evolved a genetically based latitudinal gradient in susceptibility to attack. Lipara rufitarsis, $H$. pruni, the guild of leaf chewers and the guild of internal stem feeders all exhibited non-parallel latitudinal gradients in herbivory in which a gradient was evident for the native lineage but not the invasive lineage. Ultimately, this consistent pattern indicates there is a tremendous amount of spatial heterogeneity in enemy release or biotic resistance for the invasive lineage of $P$. australis.

We offer some possible mechanisms that could lead to non-parallel latitudinal gradients in L. rufitarsis herbivory of native and invasive $P$. australis lineages. First, Lipara have only been present in North America for less than 100 years (Sabrosky, 1958; Tewksbury et al., 2002), meaning that both $P$. australis lineages have had approximately the same period of time to evolve latitudinal gradients in response to Lipara herbivory. However, because the native lineage has been present in North America for millennia, it is possible that there are pre-existing latitudinal gradients in some plant traits which may be important in determining outcomes of plantherbivore interactions. For example, leaf tissue nitrogen content, a key nutrient for many herbivores (Mattson, 1980), increased with latitude for native but not invasive $P$. australis in the field and common garden (Cronin et al., 2015; Bhattarai et al., 2016). Unfortunately, we did not quantify nitrogen content in this study, so were unable to assess whether this gradient is related to L. rufitarsis herbivory. Second, local adaptation to herbivores may be more likely for native than invasive $P$. australis populations because they have higher haplotype diversity within North America (Saltonstall, 2002, 2016). Moreover, native populations tend to be more isolated from one another and thus potentially experience less gene flow relative to invasive populations. However, this possibility is contradicted by Bhattarai et al. (2016), who observed a genetically based negative correlation between latitude and palatability to $H$. pruni aphids for the invasive $P$. australis lineage. Third, a number of studies with replicate common gardens have found that latitudinal gradients in traits associated with plant-herbivore interactions are phenotypically plastic (Woods et al., 2012; Bhattarai et al., 2016) and that invasive taxa are more plastic than native taxa (Richards et al., 2006; Davidson et al., 2011; Bhattarai et al., 2016). Thus, expression of latitudinal gradients may depend upon complex interactions between plant lineage and local environmental conditions, and the patterns observed in this study may be altered under different common garden conditions. Finally, herbivore source latitude could also be an important factor driving the presence and direction of latitudinal gradients. The L. rufitarsis used in our common garden experiment came from a single invasive $P$. australis population in Rhode Island, so may be co-adapted to plants from that latitude (Pennings et al., 2001). Indeed, Bhattarai et al. (2016) demonstrated major differences in the direction and strength of latitudinal gradients using locally sourced $H$. pruni aphids in replicate common gardens in Rhode Island and Louisiana. 
Because of the strong effect of L. rufitarsis on plant fitness through prevention of flowering (Lambert et al., 2007; Allen et al., 2015) such biogeographical heterogeneity in the strength of enemy release could potentially result in corresponding heterogeneity in establishment and spread of invasive $P$. australis. However, the effects of herbivores (including L. rufitarsis) on the fitness and demography of $P$. australis are largely unexplored. Moreover, there have been few studies that have quantified the establishment, fitness and spread of $P$. australis at different latitudes, which could more directly test whether biogeographical gradients in the strength of enemy release translate into gradients in invasion success. However, a recent study by Hughes et al. (2016) demonstrated that stem density of the invasive lineage was highest at more northern latitudes, consistent with our findings of stronger enemy release for more northern populations. In contrast, a study of historical aerial imagery from the east coast of North America found no latitudinal variation in the rate of increase of invasive $P$. australis populations (Bhattarai \& Cronin, 2014), suggesting there may be no corresponding variation in invasion success of $P$. australis.

\section{Enemy release for the invasive $\boldsymbol{P}$. australis lineage}

Although it has long been argued that leaving behind coadapted natural enemies can facilitate invasions, invasion success may ultimately depend on whether the non-native plant species can withstand the impact of herbivores in their new range (Elton, 1958; Keane \& Crawley, 2002). In support of this hypothesis (our second prediction), we found that the proportion of stems galled by L. rufitarsis was lower on the invasive than the native $P$. australis lineage in the field. This result is consistent with previous studies involving Lipara and other herbivores of $P$. australis in North America (Lambert \& Casagrande, 2007; Lambert et al., 2007; Park \& Blossey, 2008; Allen et al., 2015; Cronin et al., 2015, 2016). Because differences in herbivory could be expected to be less likely within than between species, we suggest that our study presents a conservative and phylogenetically controlled test of the enemy release hypothesis, which also accounts for biogeographical variation in plant-herbivore interactions.

Despite the strong evidence for enemy release of invasive P. australis from L. rufitarsis in the field, there was almost no difference (just 3\%) in the proportion of stems galled between native and invasive $P$. australis in the controlled common garden experiment. These data suggest that there is no genetic basis for the difference in L. rufitarsis herbivory between lineages observed in our field survey. This finding is somewhat surprising, because the invasive lineage has had a much longer co-evolutionary history with all three introduced Lipara species (all of which originate from Europe) than the native lineage and is therefore more likely to have evolved defences against attack. Multiple other studies have previously documented contrasting results between field and common garden patterns of herbivory (Park \& Blossey, 2008; Woods et al., 2012; Hiura \& Nakamura, 2013), generally attributed to the variable influence of local environmental conditions in the field (i.e. phenotypic plasticity). Thus, the discrepancy between our field and common garden studies suggests that the strong enemy release observed in the field is likely to be the result of phenotypic plasticity or legacy effects (e.g. Lipara herbivory is historically higher in association with native than invasive populations in the field), rather than genetic differences between native and invasive $P$. australis lineages. Many studies have demonstrated that invasive taxa are more phenotypically plastic than native taxa (Richards et al., 2006; Davidson et al., 2011), including within $P$. australis (Mozdzer \& Megonigal, 2012; Bhattarai et al., 2016; Douhovnikoff et al., 2016). In this study, the invasive lineage demonstrated a nearly six-fold difference in the proportion of stems galled between the field survey and common garden experiment. Thus, it is possible that the enemy release observed in the field was driven by a strong plastic response to local environmental conditions on the part of the invasive lineage.

\section{Lipara rufitarsis herbivory depends on stem characteristics}

Plant morphological traits have often been shown to be useful predictors of attack and damage by gall insects and herbivores in general (e.g. De Bruyn, 1994; Prado \& Vieira, 1999; Santos et al., 2008). In support of our fourth prediction, we found that stem characteristics during the oviposition period of $L$. rufitarsis were strongly correlated with the subsequent proportion of stems galled. Most importantly, the proportion of stems galled was much higher in those native and invasive populations that had shorter and thicker stems. However, neither of these stem characteristics varied between lineages or with latitude. Thus, differences in latitudinal gradients between the native and invasive lineage cannot be attributed to variation in stem height or diameter.

Host plant density is often cited as an important factor driving oviposition and herbivory of many gall-forming insects (e.g. Abrahamson et al., 1983; Cuevas-Reyes et al., 2004), and previous studies have found Lipara herbivory to be both positively correlated (Blossey, 2014) and unrelated (Allen et al., 2015) to stem density. In this study, we found that the proportion of stems galled by L. rufitarsis and stem density were positively correlated for the native lineage and negatively correlated for the invasive lineage. Taken together, these results suggest that for the native $P$. australis lineage, any competitive advantage gained through increased stem density may be negated by increased herbivory from $L$. rufitarsis. In contrast, the invasive lineage experiences decreased Lipara herbivory at higher stem densities.

These stem characteristics are likely to be strongly influenced by the local environment. In nature, the native and invasive lineages of $P$. australis in North America often occupy different microhabitats related to salinity, hydrology, disturbance and nutrient availability (e.g. Vasquez et al., 2005; Holdredge et al., 2010; Price et al., 2014). For example, 
native $P$. australis populations may be more prevalent in nutrient-poor environments, where they are better able to compete (Holdredge et al., 2010). This environment could result in a higher proportion of short, stressed stems, thus making the native lineage more attractive to L. rufitarsis for oviposition (De Bruyn, 1994). In a well-fertilized and watered common garden, plants were subjected to homogeneous environmental conditions and were not nutrient- or waterlimited or exposed to varying salinity levels. Therefore, lineage-specific patterns in the field (driven by microclimatic effects on stem characteristics) may be negated in a common garden.

\section{CONCLUSIONS}

We find that enemy release of the invasive $P$. australis lineage from $L$. rufitarsis is likely to be a plastic response, driven by stem characteristics that are modified by local environmental conditions rather than being the result of genetic differences between native and invasive lineages. Latitudinal variation in the strength of the enemy release is subsequently generated by local adaptation of the native but not invasive lineage along a latitudinal gradient. The result is non-parallel latitudinal variation in herbivory by $L$. rufitarsis such that the invasive lineage suffers proportionately less herbivory than the native lineage (i.e. greater enemy release) at high than low latitudes. Biogeographical variation in enemy release is widespread in $P$. australis for both generalist and specialist herbivores (this study; Cronin et al., 2015; Bhattarai et al., 2016). Unfortunately, the $P$. australis system is the only one in which the biogeography of enemy release has been explored. However, we suggest that herbivory of many cooccurring native and invasive plants with respect to latitude is likely to be dissimilar owing to many factors including different phylogenies, historical distributions and coevolutionary histories with local herbivores. Moreover, this latitudinal heterogeneity in enemy release or biotic resistance can result in corresponding heterogeneity in the establishment and spread of invasive species. On these grounds, we argue for a broader, biogeographical perspective to the study of invasive species. Moreover, because invasive species can evolve rapidly in response to environmental gradients (Maron et al., 2004; Li et al., 2015; Bhattarai et al., 2016), and native and invasive species may differ in evolutionary trajectories, differences in enemy release and biotic resistance are likely to be transient. Thus, future studies in this area should investigate temporal as well as spatial variability in interactions between invasive and native plant species. Finally, the majority of studies examining biogeographical variation in species interactions have focused on herbivory (Schemske et al., 2009). However, the importance of nonparallel latitudinal gradients for invasive and native taxa remains unexplored with respect to other species interactions such as mutualisms, competition and multi-trophic interactions, which may ultimately be important in explaining invasion success.

\section{ACKNOWLEDGEMENTS}

We would like to thank the organisations and landowners who permitted access for field surveys: Rachel Carson National Wildlife Refuge, Choptank Nature Conservancy, Alice Welford, Mackay Island National Wildlife Refuge, Pettipaug Yacht Club and Estell Manor State Park. Thanks also to R. Young, J. Croy, R. Andrews, S. Wigginton and M. Burger for lab and field assistance, and to the two anonymous referees who provided constructive comments on previous drafts of this manuscript. This project was funded by NSF grant numbers DEB 1050084 and DMS 1516833 (to J.T.C.), DEB 1501775 (to J.T.C. and W.J.A.) and DEB 1049914 (to L.A.M.), the Louisiana Environmental Education Commission (to W.J.A.), Sigma Xi Scientific Research Society (to W.J.A.) and the University of Rhode Island Agricultural Experiment Station grant number RI00H-332, 311000-6044 (to L.A.M.).

\section{REFERENCES}

Abrahamson, W.G., Armbruster, P.O. \& Maddox, G.D. (1983) Numerical relationships of the Solidago altissima stem gall insect-parasitoid guild food chain. Oecologia, 58, 351-357.

Agrawal, A.A., Kotanen, P.M., Mitchell, C.E., Power, A.G., Godsoe, W. \& Klironomos, J. (2005) Enemy release? An experiment with congeneric plant pairs and diverse aboveand belowground enemies. Ecology, 86, 2979-2989.

Alexander, H.M., Price, S., Houser, R., Finch, D. \& Tourtellot, M. (2007) Is there reduction in disease and predispersal seed predation at the border of a host plant's range? Field and herbarium studies of Carex blanda. Journal of Ecology, 95, 446-457.

Allen, W.J., Young, R.E., Bhattarai, G.P., Croy, J.R., Lambert, A.M., Meyerson, L.A. \& Cronin, J.T. (2015) Multitrophic enemy escape of invasive Phragmites australis and its introduced herbivores in North America. Biological Invasions, 17, 3419-3432.

Anstett, D.N., Naujokaitis-Lewis, I. \& Johnson, M.T.J. (2014) Latitudinal gradients in herbivory on Oenothera biennis vary according to herbivore guild and specialization. Ecology, 95, 2915-2923.

Balme, G. (2000) Insects on Phragmites australis. Master's Thesis, University of Rhode Island, Kingston, RI.

Barton, K. (2016) MuMIn: model selection and model averaging based on information criteria (AICc and alike).R package version 1.15.6. Available at: http:/CRAN.R-project.org/package $=$ MuMIn.

Bezemer, T.M., Harvey, J.A. \& Cronin, J.T. (2014) Response of native insect communities to invasive plants. Annual Review of Entomology, 59, 119-141.

Bhattarai, G.P. \& Cronin, J.T. (2014) Hurricane activity and the large-scale pattern of spread of an invasive plant species. PLOS ONE 9, e98478. doi:10.1371/journal.pone. 0098478.

Bhattarai, G.P., Meyerson, L.A., Anderson, J., Cummings, D., Allen, W.J. \& Cronin, J.T. (2016) Biogeography of a plant invasion: genetic variation and plasticity in latitudinal 
clines for traits related to herbivory. Ecological Monographs, doi:10.1002/ecm.1233.

Blossey, B. (2014) Identification, development, and release of insect biocontrol agents for the management of Phragmites australis. ERDC/EL CR-14-2. US Army Corps of Engineers, Washington DC.

Burnham, K.P. \& Anderson, D.R. (2010) Model selection and multimodel inference: a practical information-theoretic approach, 2nd edn. Springer, New York.

Chambers, R.M., Meyerson, L.A. \& Saltonstall, K. (1999) Expansion of Phragmites australis into tidal wetlands of North America. Aquatic Botany, 64, 261-273.

Chun, Y.J., van Kleunen, M. \& Dawson, W. (2010) The role of enemy release, tolerance and resistance in plant invasions: linking damage to performance. Ecology Letters, 13, 937-946.

Chvala, M., Doskocil, J., Mook, J.H. \& Pokorny, V. (1974) The genus Lipara Meigen (Diptera, Chloropidae), systematics, morphology, behaviour, and ecology. Tijdschrift voor Entomologie, 117, 1-25.

Colautti, R.I., Ricciardi, A., Grigorovich, I.A. \& MacIsaac, H.J. (2004) Is invasion success explained by the enemy release hypothesis. Ecology Letters, 7, 721-733.

Coley, P.D. \& Aide, T. (1991) Comparison of herbivory and plant defenses in temperate and tropical broad-leaved forests. Plant-animal interactions: evolutionary ecology in tropical and temperate regions (ed. by P.W. Price, T.M. Lewinsohn, G.W. Fernandes and W.W. Benson), pp. 25-49. Wiley-Interscience, Hoboken, NJ.

Cronin, J.T., Bhattarai, G.P., Allen, W.J. \& Meyerson, L.A. (2015) Biogeography of a plant invasion: plant-herbivore interactions. Ecology, 96, 1115-1127.

Cronin, J.T., Kiviat, E., Meyerson, L.A., Bhattarai, G.P. \& Allen, W.J. (2016) Biological control of invasive Phragmites australis will be detrimental to native P. australis. Biological Invasions, 18, 2749-2752.

Cuevas-Reyes, P., Quesada, M., Hanson, P., Dirzo, R. \& Oyama, K. (2004) Diversity of gall-inducing insects in a Mexican tropical dry forest: the importance of plant species richness, life-forms, host plant age and plant density. Journal of Ecology, 92, 707-716.

Davidson, A.M., Jennions, M. \& Nicotra, A.B. (2011) Do invasive species show higher phenotypic plasticity than native species and, if so, is it adaptive? A meta-analysis. Ecology Letters, 14, 419-431.

De Bruyn, L. (1994) Life cycle strategies in a guild of dipteran gall formers on the common reed. Plant-galls: organisms, interactions, populations (ed. by M. Williams), pp. 259-282. Clarendon Press, Oxford.

Dlugosch, K.M. \& Parker, I.M. (2008) Founding events in species invasions: genetic variation, adaptive evolution, and the role of multiple introductions. Molecular Ecology, 17, 431-449.

Dobzhansky, T. (1950) Evolution in the tropics. American Scientist, 38, 209-221.
Douhovnikoff, V., Taylor, S.H., Hazelton, E.L.G., Smith, C.M. \& O'Brien, J. (2016) Maximal stomatal conductance to water and plasticity in stomatal traits differ between native and invasive introduced lineages of Phragmites australis in North America. AoB Plants, 8, plw006. doi:10.1093/aobpla/ plw006.

Elton, C.S. (1958) The ecology of invasions by animals and plants. University of Chicago Press, Chicago, IL.

Hauber, D.P., Saltonstall, K., White, D.A. \& Hood, C.S. (2011) Genetic variation in the common reed, Phragmites australis, in the Mississippi River Delta marshes: evidence for multiple introductions. Estuaries and Coasts, 34, 851-862.

Hillebrand, H. (2004) On the generality of the latitudinal diversity gradient. The American Naturalist, 163, 192-211.

Hiura, T. \& Nakamura, M. (2013) Different mechanisms explain feeding type-specific patterns of latitudinal variation in herbivore damage among diverse feeding types of herbivorous insects. Basic and Applied Ecology, 14, 480-488.

Holdredge, C., Bertness, M.D., von Wettberg, E. \& Silliman, B.R. (2010) Nutrient enrichment enhances hidden differences in phenotype to drive a cryptic plant invasion. Oikos, 119, 1776-1784.

Howard, R.J., Travis, S.E. \& Sikes, B.A. (2008) Rapid growth of a Eurasian haplotype of Phragmites australis in a restored brackish marsh in Louisiana, USA. Biological Invasions, 10, 369-379.

Hughes, A.R., Schenck, F.R., Bloomberg, J., Hanley, T.C., Feng, D., Gouhier, T.C., Beighley, R.E. \& Kimbro, D.L. (2016) Biogeographic gradients in ecosystem processes of the invasive ecosystem engineer Phragmites australis. Biological Invasions, 18, 2577-2595.

Keane, R.M. \& Crawley, M.J. (2002) Exotic plant invasions and the enemy release hypothesis. Trends in Ecology and Evolution, 17, 164-170.

Kim, T.N. (2014) Plant damage and herbivore performance change with latitude for two old-field plant species, but rarely as predicted. Oikos, 123, 886-896.

Kulmatiski, A., Beard, K.H., Meyerson, L.A., Gibson, J.R. \& Mock, K.E. (2010) Nonnative Phragmites australis invasion into Utah wetlands. Western North American Naturalist, 70, 541-552.

Lambert, A.M. \& Casagrande, R.A. (2007) Susceptibility of native and non-native common reed to the non-native mealy plum aphid (Homoptera: Aphididae) in North America. Environmental Entomology, 36, 451-457.

Lambert, A.M., Winiarski, K. \& Casagrande, R.A. (2007) Distribution and impact of exotic gall flies (Lipara sp.) on native and exotic Phragmites australis. Aquatic Botany, 86, 163-170.

Lambertini, C., Gustafsson, M.H.G., Frydenberg, J., Lissner, J., Speranza, M. \& Brix, H. (2006) A phylogeographic study of the cosmopolitan genus Phragmites (Poaceae) based on AFLPs. Plant Systematics and Evolution, 258, $161-182$. 
Levine, J.M., Adler, P.B. \& Yelenik, S.G. (2004) A metaanalysis of biotic resistance to exotic plant invasions. Ecology Letters, 7, 975-989.

Li, X.M., She, D.Y., Zhang, D.Y. \& Liao, W.J. (2015) Life history trait differentiation and local adaptation in invasive populations of Ambrosia artemisiifolia in China. Oecologia, 177, 669-677.

Liu, H. \& Stiling, P. (2006) Testing the enemy release hypothesis: a review and meta-analysis. Biological Invasions, 8, 1535-1545.

Maron, J.L., Vilà, M., Bommarco, R., Elmendorf, S. \& Beardsley, P. (2004) Rapid evolution of an invasive plant. Ecological Monographs, 74, 261-280.

Mattson, W.J., Jr. (1980) Herbivory in relation to plant nitrogen content. Annual Review of Ecology and Systematics, 11, 119-161.

Meadows, R.E. \& Saltonstall, K. (2007) Distribution of native and introduced Phragmites australis in freshwater and oligohaline tidal marshes of the Delmarva Peninsula and southern New Jersey. Journal of the Torrey Botanical Society, 134, 99-107.

Menard, S. (2000) Coefficients of determination for multiple logistic regression analysis. American Statistician, 54, 17-24.

Meyerson, L.A., Saltonstall, K. \& Chambers, R.M. (2009) Phragmites australis in eastern North America: a historical and ecological perspective. Human impacts on salt marshes: a global perspective (ed. by B.R. Silliman, E. Grosholz and M.D. Bertness), pp. 57-82. University of California Press, Los Angeles, CA.

Meyerson, L.A., Lambertini, C., McCormick, M.K. \& Whigham, D.F. (2012) Hybridization of common reed in North America? The answer is blowing in the wind. $A o B$ Plants, 2012, pls022. doi:10.1093/aobpla/pls022.

Meyerson, L.A., Cronin, J.T. \& Pyšek, P. (2016) Phragmites as a model organism for studying plant invasions. Biological Invasions, 18, 2421-2431.

Mitchell, C.E., Agrawal, A.A., Bever, J.D., Gilbert, G.S., Hufbauer, R.A., Klironomos, J.N., Maron, J.L., Morris, W.F., Parker, I.M., Power, A.G., Seabloom, E.W., Torchin, M.E. \& Vázquez, D.P. (2006) Biotic interactions and plant invasions. Ecology Letters, 9, 726-740.

Moles, A.T., Bonser, S.P., Poore, A.G.B., Wallis, I.R. \& Foley, W.J. (2011) Assessing the evidence for latitudinal gradients in plant defence and herbivory. Functional Ecology, 25, 380-388.

Mozdzer, T.J. \& Megonigal, J.P. (2012) Jack-and-Master trait responses to elevated $\mathrm{CO}_{2}$ and $\mathrm{N}$ : a comparison of native and introduced Phragmites australis. PLoS One, 7, e42794. doi:10.1371/journal.pone.0042794.

Park, M.G. \& Blossey, B. (2008) Importance of plant traits and herbivory for invasiveness of Phragmites australis (Poaceae). American Journal of Botany, 95, 1557-1568.

Parker, I.M. \& Gilbert, G.S. (2007) When there is no escape: the effects of natural enemies on native, invasive, and noninvasive plants. Ecology, 88, 1210-1224.
Parker, J.D., Burkepile, D.E. \& Hay, M.E. (2006) Opposing effects of native and exotic herbivores on plant invasions. Science, 311, 1459-1461.

Pennings, S.C., Siska, E.L. \& Bertness, M.D. (2001) Latitudinal differences in plant palatability in Atlantic Coast salt marshes. Ecology, 82, 1344-1359.

Pianka, E.R. (1966) Latitudinal gradients in species diversity: a review of concepts. The American Naturalist, 100, 33-46.

Prado, P.I.K.L. \& Vieira, E.M. (1999) The interplay between plant traits and herbivore attack: a study of a stem galling midge in the Neotropics. Ecological Entomology, 24, $80-88$.

Price, A.L., Fant, J.B. \& Larkin, D.J. (2014) Ecology of native vs. introduced Phragmites australis (common reed) in Chicago-area wetlands. Wetlands, 34, 369-377.

R Development Core Team. (2016) R: a language and environment for statistical computing. R Foundation for Statistical Computing, Vienna, Austria. Available at: http://www. R-project.org.

Richards, C.L., Bossdorf, O., Muth, N.Z., Gurevitch, J. \& Pigliucci, M. (2006) Jack of all trades, master of some? On the role of phenotypic plasticity in plant invasions. Ecology Letters, 9, 981-993.

Sabrosky, C.W. (1958) A Phragmites gall-maker new to North America (Diptera, Chloropidae). Proceedings of the Entomological Society of Washington, 60, 231.

Saltonstall, K. (2002) Cryptic invasion by a non-native genotype of the common reed, Phragmites australis, into North America. Proceedings of the National Academy of Sciences USA, 99, 2445-2449.

Saltonstall, K. (2016) The naming of Phragmites haplotypes. Biological Invasions, 18, 2433-2441.

Santos, J.C., Silveira, F.A.O. \& Fernandes, G.W. (2008) Long term oviposition preference and larval performance of Schizomyia macrocapillata (Diptera: Cecidomyiidae) on larger shoots of its host plant Bauhinia brevipes (Fabaceae). Evolutionary Ecology, 22, 123-137.

Schemske, D.W., Mittelbach, G.G., Cornell, H.V., Sobel, J.M. \& Roy, K. (2009) Is there a latitudinal gradient in the importance of biotic interactions? Annual Review of Ecology Evolution and Systematics, 40, 245-269.

Shea, K. \& Chesson, P. (2002) Community ecology theory as a framework for biological invasions. Trends in Ecology and Evolution, 17, 170-176.

Tewksbury, L., Casagrande, R., Blossey, B., Hafliger, P. \& Schwarzlander, M. (2002) Potential for biological control of Phragmites australis in North America. Biological Control, 23, 191-212.

Vachon, N. \& Freeland, J.R. (2011) Phylogeographic inferences from chloroplast DNA: quantifying the effects of mutations in repetitive and non-repetitive sequences. Molecular Ecology Resources, 11, 279-285.

Vasquez, E.A., Glenn, E.P., Brown, J.J., Guntenspergen, G.R. \& Nelson, S.G. (2005) Salt tolerance underlies the 
cryptic invasion of North American salt marshes by an introduced haplotype of the common reed Phragmites australis (Poaceae). Marine Ecology Progress Series, 298, $1-8$.

Woods, E.C., Hastings, A.P., Turley, N.E., Heard, S.B. \& Agrawal, A.A. (2012) Adaptive geographical clines in the growth and defense of a native plant. Ecological Monographs, 82, 149-168.

\section{SUPPORTING INFORMATION}

Additional supporting information may be found in the online version of this article at the publisher's web-site:

Appendix S1 List of Phragmites australis field populations surveyed for the proportion of stems galled by Lipara.

Appendix S2 List of Phragmites australis populations used for the common garden experiment at the University of Rhode Island.

Appendix S3 Results from generalised linear model analyses for the effects of latitude, latitude ${ }^{2}$ and stem characteristics during the Lipara rufitarsis oviposition period on the proportion of stems galled of the native and invasive lineages of Phragmites australis in the common garden experiment.

\section{BIOSKETCH}

Warwick Allen is a post-doctoral fellow at The BioProtection Research Centre, Lincoln University, New Zealand. This work was carried out during his $\mathrm{PhD}$ at Louisiana State University. His research interests include the causes and consequences of biological invasions, with a specific focus on the role of direct and indirect species interactions on the success of invasive species and biological control.

This research group aims to study the role of multitrophic interactions, plant genetics, plasticity and biogeography in driving plant invasions at large spatial scales. They are also members of PhragNet, a global research network that uses Phragmites australis as a model organism for studying plant invasions.

Editor: Angela Moles 